\title{
Negotiating early Anglo-Saxon cemetery space
}

\section{Introduction}

The dead aren't dead until the living have recorded their deaths in narratives. Death is a matter of archives. You are dead when stories are told about you, and when only stories are told about you (Lyotard and Benjamin, 1989: 126)

Today, ancient cemeteries are being rediscovered underneath rural landscapes, on the edges of ancient boundaries, or buried in the heart of villages and towns. But early medieval cemeteries were not forgotten places set aside for the dead, they were ancient repositories, archives where the dead and their stories were consigned to be recounted in the construction of community identities. The landscape acted as a meeting place for the living and their dead, making safe the bodies of relatives and associates, rooting community and memory into physical space. Cemeteries were not simply mortuary landscapes, they were pluralistic spaces used by the living who constructed them and who created experiences which situated cemeteries, performance and funerals within the spheres of personal and communal life.

Funerary narratives can be shared or internalised and may be supported with material culture: a spear placed in a grave or an heirloom brooch (Williams, 2007). Narratives can also take place at different scales using material and spatial foundations: burial under a mound, next to a partner, child, parent, grandparent or important person. As a result cemeteries are multi-generational histories, spatial representations of how a community described itself internally and to others. And, like other histories, dominant narratives were reinterpreted as each generation created its own discourses. Consequently, each cemetery is the unique and complex product of multiple agents working at different times. Each grave was the end result of a funeral designed by multiple architects working within specific chronological and personal circumstances and influenced by social agents which extended across 
peopled landscapes. At the graveside, funeral participants negotiated the details of a burial through participation. Part of this negotiation included decisions about the deceased's place within the contemporary community narrative - a choice was made to maintain or reject an existing epitome - and this negotiation affected the location of a grave, and the material culture included with a corpse. Consequently, the grave, the cemetery and the funeral were assembled within a familial circumstance which was part of a wider political situation; some individuals would have been buried locally, but others, influenced by regional agendas, may have been transported as corpses to another, specific site for burial (Sayer, 2014).

Material culture, burials, cemeteries and political landscapes were the product of social structures dependent on lifeways and objects, which are integral in expressing and transmitting human social relationships (Lupton, 1998: 143). In archaeology, as with many other social sciences, these structures can be understood to exist in the relationships between people. Archaeologically, we might consider the physical and the material remains of the past as an invention of interpersonal interaction. Thus we should consider that funerary decisions were the result of complex or incomplete social negotiations, with multiple layers and mutable agents presiding over different agendas and influence. Grave 78 from the early Anglo-Saxon cemetery at Oakington, Cambridgeshire, is a good example. This grave contained two individuals, an adult woman and a child (Figure 1.1), and the adult was placed prone with her legs crossed at the ankle as if tied, a position dissimilar to but reminiscent of the allegedly live burial from Sewerby, East Yorkshire (grave 41, Hirst, 1985). The prone body position seen in these two examples is a phenomenon seen in only 1 per cent of excavated early Anglo-Saxon graves and it seems to have re-emerged in the mid-sixth century AD (Stoodley, 1999: 55; Lucy, 2000a). This position has been described as a special burial rite and, as with the Sewerby example, archaeologists have associated prone burial with a violent death; or one in which the prone position made safe a dangerous corpse (Wilson, 1992; O’Brien, 1999; Reynolds, 2009: 75; Williams, 2007).

The interaction of the two individuals in grave 78 at Oakington is vital to its interpretation. The adult woman's right arm was located under her chest, her hand emerging at the shoulder and grasping a small, long brooch and glass beads. Her left arm was deliberately positioned under her abdomen so that her hand emerged on her right and rested on top of the child's upper left arm. The child had been placed lying on its right side, head facing or looking at the adult. Importantly the adult's wrist clasps were found on top of the child's arm; her arm had been positioned purposely to touch the child but this interaction 


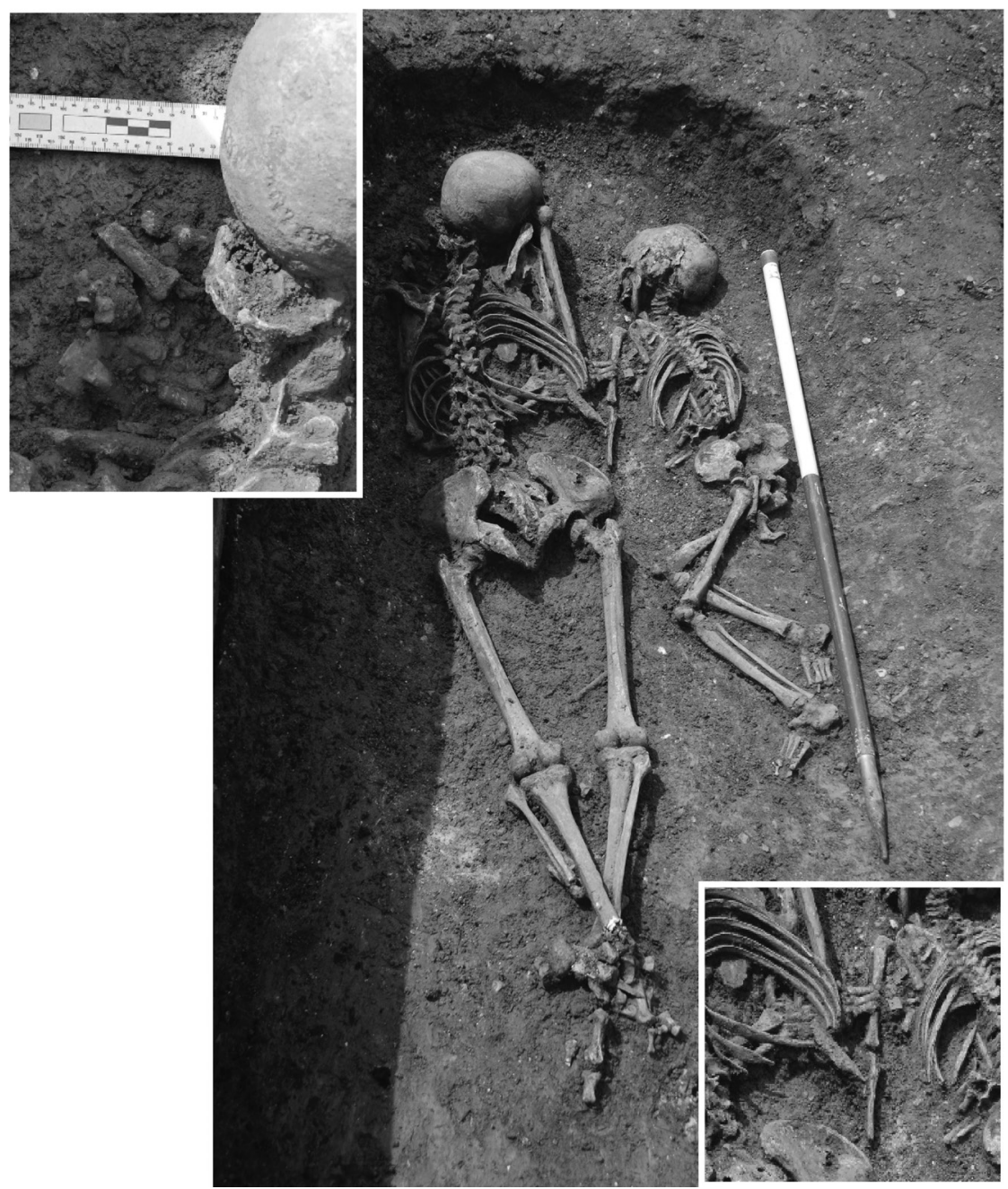

Figure 1.1 Grave 78 from Oakington. The double grave contained a woman and child. The woman was buried prone, holding a brooch and beads in her right hand. Her left hand rested on the child's arm.

was subsequently concealed with her sleeve. We can safely assume that the clasps were associated with the adult's wrist and not the child's dress because this dress item is commonly associated with adult females (over the age of about 20), and to a much lesser degree adolescents or older children, but never young children as in this case (Stoodley 1999: 231).

The grave soils in grave 78 contained no evidence of grave reopening, and the adult and child must have been buried at the same time. 
The graveside experience was deliberately staged by the exhibition of a woman buried face down, and possibly bound to make her corpse safe. A second more subtle message was embedded within the funerary performance and would have been understood by just a few people, those who laid out the bodies and knew that the woman and child were intimately connected and buried together in the earth. The meanings entangled within this performance may have been deliberately ambiguous; her right hand clutched her beads, tightly protected by her shoulder, and away from an 'assailant' or observer. This is reminiscent of a live burial, but this intimacy is hard to reconcile with violence; it is a cherished position, subtle and too familiar. In this case, both arms were under the corpse and would have been hard to position without climbing into the grave, so the people who laid out her body would be close in with her, entangling their own bodies with the two corpses.

Funerals carried multiple messages; some were concealed, shared by just a few, and others were meant for many participants to witness. These messages were intended for a variety of people who shared different understandings, had different roles and different ways of participating in the funeral events. The example of Oakington's grave 78 is important because the physical concealment of a touch is not just a hidden gesture but could also be read as the manifestation of selective knowledge. Particular members of a funeral party might understand localised ways of preparing or dressing the dead (see Chapter 2); others may not have shared in that knowledge but participated in the event from a different perspective based on their relatedness to the funerary party, their role in the proceedings and previous experiences. Funerary negotiations can include scales of inclusion, scales of participation and practice. These conflicting perspectives are the essence of the constant renegotiation which ensues between generations of people who reinterpret their place within society as their life courses unfolded. So burial was a palimpsest, its purpose and meaning reinterpreted by individuals and generations, depending on community and personal circumstances. Because of these things each burial was the result of one set of decisions and depended on who was being interred and who was present at their funeral to make these decisions. Nevertheless, how a burial or cemetery was understood also depended on how previous inhumations were explained, who was relating that narrative, and the composition of their audience. These events entered social memory as an aural archive of stories replayed and reinterpreted at every retelling; recitations might also take place in between funerals, as part of routine life or at significant times and gatherings in the community calendar.

Importantly, the multi-scaled multi-dimensionality of the mortuary context means that archaeology can understand and interpret past 
behaviours. Past people created narratives and these stories were meant to be understood by dissimilar people with varying amounts of knowledge at different times. Past people cannot have imagined archaeological methods, and yet archaeologists are late audiences taking interpretive narratives from funeral spaces. These spaces are understandable because their multiple architects intended them to work as an aide-mémoire with which to negotiate community histories with shared semiotic understanding. This book describes a number of Anglo-Saxon cemeteries (Figure 1.2) and defines the archaeological evidence for the people found in those graves. It considers this evidence as being the result of a nexus of identities established by their relationship with others. It explores a variety of themes, including taphonomy, space, life course, gender, objects and osteology, within the context of cemetery organisation and regional circumstances. Early Anglo-Saxon cemeteries were the physical manifestation of community histories and early Anglo-Saxon societies; and they were textured, mutable, dynamic places within which personal, community and landscape identities were persistently negotiated, renegotiated and reinterpreted.

\section{Approaching cemetery space}

The earliest reports about Anglo-Saxon cemeteries were the results of eighteenth-century excavation. Attractive illustrations focused on gravegoods and occasionally reproduced images of the wealthiest graves (Williams, 2009). It was only in the 1930s that the less wealthy, but more typical, early Anglo-Saxon graves were also illustrated, albeit with a focus on the 'warrior burial' (Williams, 2009: 171-2). By the 1960s and 1970s, cemetery plans began to routinely appear in excavation reports. Sonia Chadwick Hawkes, as well as Calvin Wells and Charles Green, tried to connect this spatial information with deliberate behaviours and noted the presence of patterns in cemeteries. They investigated the location and orientation of graves and attempted to link these factors to the time of year that a burial was made (Chadwick Hawkes, 1977; Wells and Green, 1973). Called sunrise dating, this approach has been discredited because it tended to concentrate population mortality into the summer months, based on the angle of a grave and the position of the sun. Subsequent investigation of ethnographic evidence reveals that death in pre-industrial society was more likely in the winter because of the cold and the relative scarcity of food (Brown, 1983; Rahtz, 1978; Bullough, 1983; Boddington, 1990; Kendall, 1982).

Also in the 1970s, Lewis Binford observed that archaeological sites were the product of human agency and he hypothesised that they would contain spatial clustering, which could be investigated 

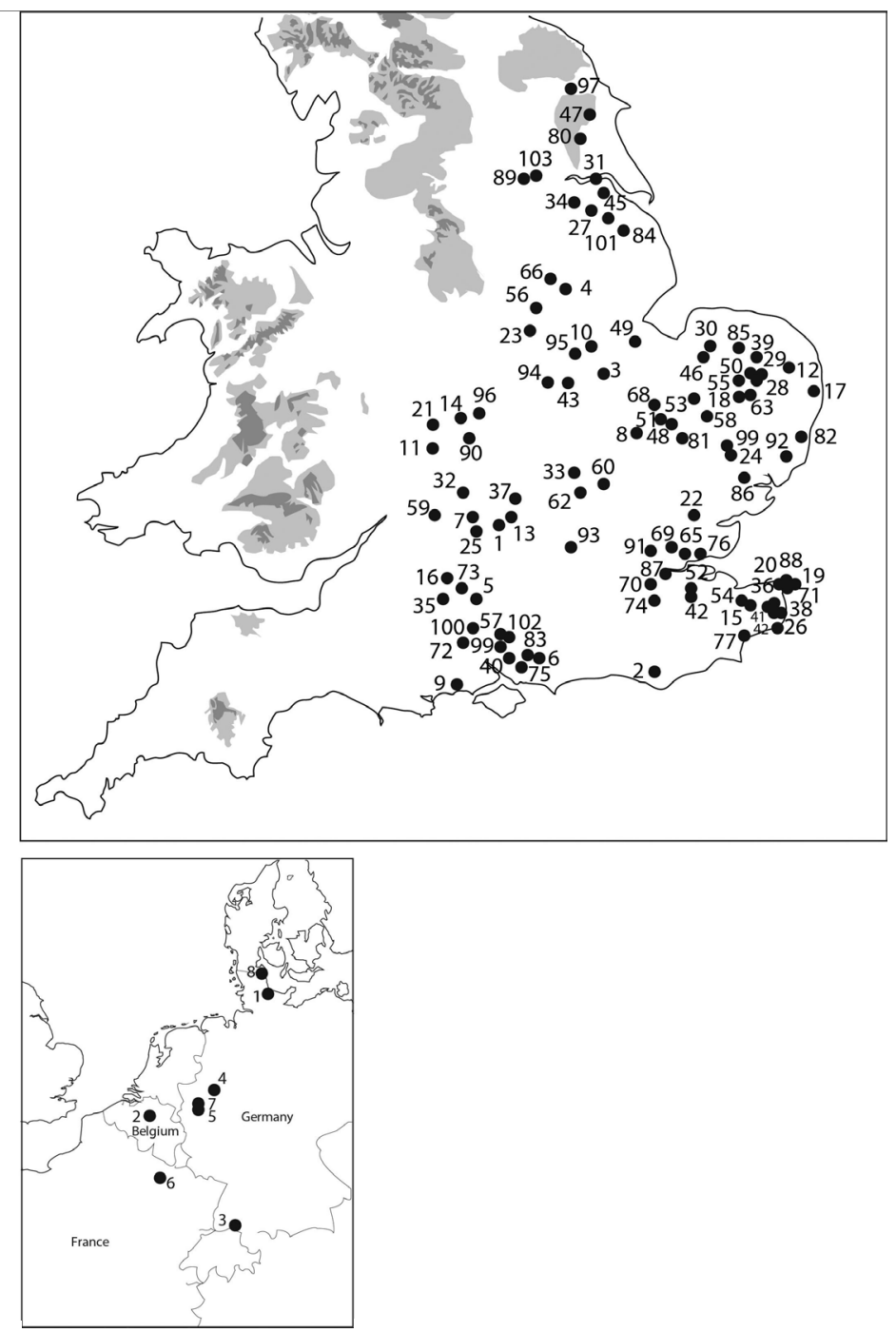

Figure 1.2 The distribution of cemeteries mentioned in this book:

1. Abingdon I, Upper Thames

2. Alfriston, Sussex

3. Alwalton, Cambridgeshire

4. Ancaster, Lincolnshire

5. Andover, Hampshire

6. Apple Down, West Sussex

7. Asthall, Oxfordshire

8. Barrington, Cambridgeshire

9. Bargates, Dorset

10. Baston, Lincolnshire
11. Beckford B, Worcestershire

12. Bergh Apton, Norfolk

13. Berinsfield, Oxfordshire

14. Bidford-on-Avon, Warwickshire

15. Bifrons, Kent

16. Blacknall Field, Wiltshire

17. Bloodmoor Hill, Suffolk

18. Brettenham, Norfolk

19. Bradstow School, Kent

20. Broadstairs I, Kent 
21. Broadway Hill, Worcestershire

22. Broomfield, Essex

23. Broughton Lodge, Nottinghamshire

24. Boxford, Suffolk

25. Brighthampton, Oxfordshire

26. Buckland, Dover, Kent

27. Caenby, Lincolnshire

28. Caistor St Edmund, Norfolk

29. Caistor-by-Norwich, Norfolk

30. Castle Acre, Norfolk

31. Castledyke, North Lincolnshire

32. Chadlington, Oxfordshire

33. Chamberlains Barn II, Bedfordshire

34. Cleatham, Lincolnshire

35. Collingbourne Ducis, Wessex

36. Coombe, Kent

37. Cuddesdon, Oxfordshire

38. Deal, Kent

39. Drayton, Norfolk

40. Droxford, Hampshire

41. Eastry, Kent

42. Eccles, Kent

43. Empingham II, Rutland

44. Finglesham, Kent

45. Fonaby, Lincolnshire

46. Gallows Hill, Swaffham Prior, Cambridgeshire

47. Garton Slack II, East Yorkshire

48. Great Chesterford, Essex

49. Hall Hill, Lincolnshire

50. Harford Farm, Norfolk

51. Hatherdene, Cambridgeshire

52. Holborough, Kent

53. Holywell Row, Suffolk

54. Howletts, Kent

55. Illington, Norfolk

56. Kingston-on-Soar, Nottinghamshire

57. Kingsworthy, Hampshire

58. Lackford, Suffolk

59. Lechlade, Gloucestershire

60. Leighton Buzzard II and III, Bedfordshire

61. Lyminge, Kent

62. Marina Drive, Bedfordshire

63. Market Lavington, Wiltshire

64. Morning Thorpe, Norfolk

65. Mucking, Essex

66. Newark, Nottinghamshire

67. Norton, Cleveland (was in Co. Durham)

68. Oakington, Cambridgeshire
69. Orsett, Essex

70. Orpington, Kent

71. Ozengell, Kent

72. Petersfinger, Wiltshire

73. Pewsey, Wiltshire

74. Polhill, Kent

75. Ports Down I, Hampshire

76. Prittlewell, Essex

77. Saltwood, Kent

78. Sancton, East Yorkshire

79. Sarre, Kent

80. Sewerby, East Yorkshire

81. Shudy Camps, Cambridgeshire

82. Snape, Suffolk

83. Snell's Corner, Hampshire

84. South Elkington, Lincolnshire

85. Spong Hill, Norfolk

86. Springfield Lyons, Essex

87. Springhead, Northfleet, Kent

88. St Peters, Kent

89. Street House, Yorkshire

90. Stretton-on-Fosse, Warwickshire

91. Stifford Clays, Essex

92. Sutton Hoo, Suffolk

93. Taplow, Buckinghamshire

94. Thurmaston, Leicestershire

95. Wakerley, Northamptonshire

96. Wasperton, Warwickshire

97. West Heslerton, East Yorkshire

98. Westgarth Gardens, Suffolk

99. Winnall II, Hampshire

100. Winterbourne Gunner, Wiltshire

101. Wold Newton, Lincolnshire

102. Worthy Park, Kings Worthy, Hampshire

103. Tanner's Row, Pontefract, West Yorkshire

\section{Continental Cemeteries}

1. Bordesholm, Schleswig-Holstein, Germany

2. Bossut-Gottechain, Belgium

3. Bülach, Cologne, Germany

4. Dortmund-Wickede, Germany

5. Junkersdorf, Cologne, Germany

6. Lavoye, Le Haie des Vaches, Northern France

7. Müngersdorf, Cologne, Germany

8. Süderbrarup, Angeln, SchleswigHolstein, Germany 
by studying material remains (Binford, 1971). The simplicity of this notion was criticised by Ellen-Jane Pader who conducted a detailed investigation of two early Anglo-Saxon cemeteries, Holywell Row and Westgarth Gardens (both in Suffolk), and compared them to two sites that she studied in less detail, Bergh Apton, Norfolk, and Boxford, Suffolk (Pader, 1980; 1982). Using mathematical serration for grouping similarities in gravegood assemblages and body positions, Pader developed a multi-variate analysis, which considered differences in depositional practice between graves. Similarly, but without the statistics, Vera Evison (1987), produced a detailed spatial analysis of Dover Buckland. She identified spatial groups based on the physical clustering of graves, according to the location of adults of different genders. Both authors divided their respective cemeteries into small groups focused on a handful of furnished graves; however, their collective attention on the contents of each burial meant that their results tended to marginalise the physical clustering of the graves themselves. These two approaches also tended to ignore the chronological immediacy of burial, favouring instead the identification of small nuclear-family-like units.

The cemetery plans newly available to Hope-Taylor in the 1970s led him to observe that early Anglo-Saxon cemeteries had either a single focus or multiple foci around which the graves were clustered (HopeTaylor, 1977: 262). After a prolonged study of 'inadequate records' he proposed that this monocentric or polycentric basis was chronological, with an earlier grave or monument defining a central point. Building on Brian Hope-Taylor's observations, and with access to more published and unpublished site plans, Heinrich Härke considered the foci of burial plots in conjunction with a generalised dating scheme based on male graves (Härke, 1992: 169-70). He compared the horizontal stratigraphy from twenty sites and concluded that there were four main types of cemetery (see Table 1.1): 1) horizontal, where a single direction of burial formed over time; 2 ) monocentric, where there was a single point from which burials radiated out over time in several directions; 3 ) polycentric, with the simultaneous development of several areas; 4) irregular, with no clear pattern.

These conceptualisations of cemetery space were a useful starting point and laid a foundation which has since been used to describe mortuary landscapes. Subsequent excavation reports have considered the horizontal development of cemeteries or the focus of burial. For example, Dover Buckland was considered to have a horizontal chronology from west [earlier] to east [later] (Evison, 1987: 136, 372-8, see Figure 1.3) whereas Blacknall Field, Wiltshire, has been interpreted as a polyfocal cemetery (Annable and Eagles, 2010: 103). Before the recent 
Table 1.1 Horizontal stratigraphy in Anglo-Saxon cemeteries (adapted from Härke, 1992: 171, tab 26, and Härke, 1997: 138)

\begin{tabular}{lll}
\hline Horizontal stratigraphy & Cemetery & Region \\
\hline borizontal & Finglesham & Kent \\
monocentral multi-directional & Petersfinger & Wessex \\
monocentral multi-directional & Collingbourne Ducis & Wessex \\
monocentral multi-directional & Berinsfield & Upper Thames \\
monocentral multi-directional & Bergh Apton & East Anglia \\
monocentral unclear development & Snell's Corner & Wessex \\
polycentric & Broadstairs I & Kent \\
polycentric & Polhill & Kent \\
polycentric & Mucking II & Essex \\
polycentric & Alfriston & Sussex \\
polycentric & Worthy Park & Wessex \\
polycentric & Andover & Wessex \\
polycentric & Pewsey & Wessex \\
polycentric & Stretton-on-Fosse & West Midlands \\
polycentric & Wakerley I & East Midlands \\
polycentric & Spong Hill (inhumations) & East Anglia \\
polycentric & Holywell Row & East Anglia \\
polycentric & Westgarth Gardens & East Anglia \\
polycentric & Sewerby & Northern England \\
irregular & Abingdon I & Upper Thames \\
\hline
\end{tabular}

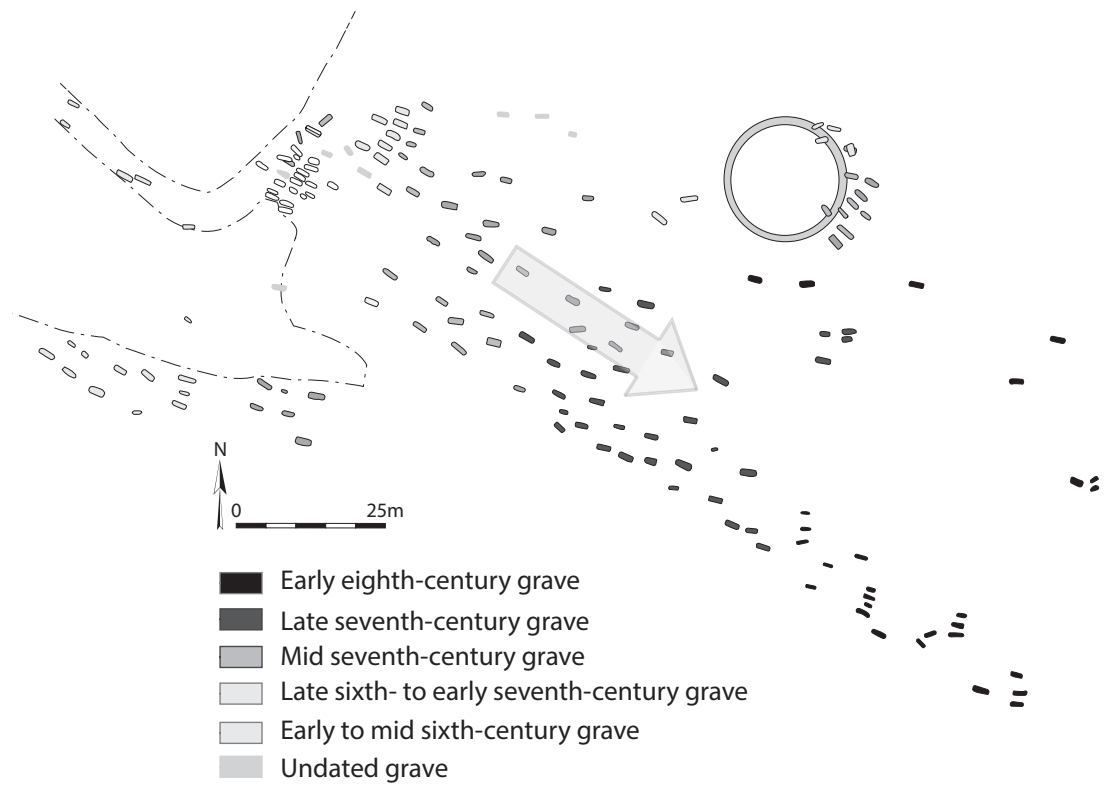

Figure 1.3 Evison's 1987 interpretation of a horizontal chronology at Dover Buckland, Kent. She considered the earliest graves to be in the north-west. 
reassessment of its chronology, the large cremation cemetery found at Spong Hill, Norfolk, was considered to have radiated out from an earlier internal zone or zones (Hills, 1994: 42). Because it did not compare with other sites, Lechlade, Gloucestershire, was described as an irregular site with little evidence of clear spatial sequence (Boyle et al., 2011: 129-45). As chapters 2 and 6 will show, Lechlade is complex and multi-phased but compares well with other sites. Spong Hill is very complex, with multi-phased activity, but each phase took a different pattern (Hills and Lucy, 2013: 213-32).

It is important to understand the chronology of a cemetery, but traditional methods expected adjacent graves to have comparable dates, an understanding that has been discredited (Ucko, 1969: 276-7). This approach is called 'horizontal stratigraphy' but, despite its name, it has very little to do with actual stratigraphy and is based on the assumption that cemeteries spread from an earlier point or points. In practice, most cemeteries are complex with multiple variables and many have no obvious single initial centre, so cannot be described as mono- or polycentral based on an exclusively chronological model. Burials were made by distinct groups of people at various times, and they chose to focus on different characteristics within the site. The studies by Härke and Hope-Taylor were based on the data available at the time of investigation, but they also tended to look for simple patterns to allow the comparison of cemeteries within and across regions. Finglesham, Kent, for example, exhibits a general trend for north-to-south drift over time and, based on male graves, Härke described it as horizontal (Härke, 1992: 171). However, when male and female graves are studied together, it becomes apparent that many later graves were placed on the northern part of the site and some early ones can be found in the southern part (Figure 1.4). Finglesham's seventh-century graves can be seen more frequently on the edges of the cemetery, suggesting a trend towards the placement of the dead at the edges of the site. But this is too simple. Finglesham actually exhibits multiple simultaneous chronological patterning with some burials placed at the edges of the cemetery and others focused around key burials positioned under mounds so that they become focal points (see chapters 2 and 3). Berinsfield, Oxfordshire, did not have a single earlier focus either, but exhibited multiple areas of continued emphasis throughout its sixth- and short-lived seventh-century use. Focal points rarely have one early date because they were visited and revisited during multiple generations and during different phases of activity as the architects of each grave chose to follow or reject the patterns established by their predecessors (Sayer, 2010).

In Härke's (1995) study of Berinsfield, based on the male gravegoods, he suggested that the cemetery developed horizontally in two cardinal 


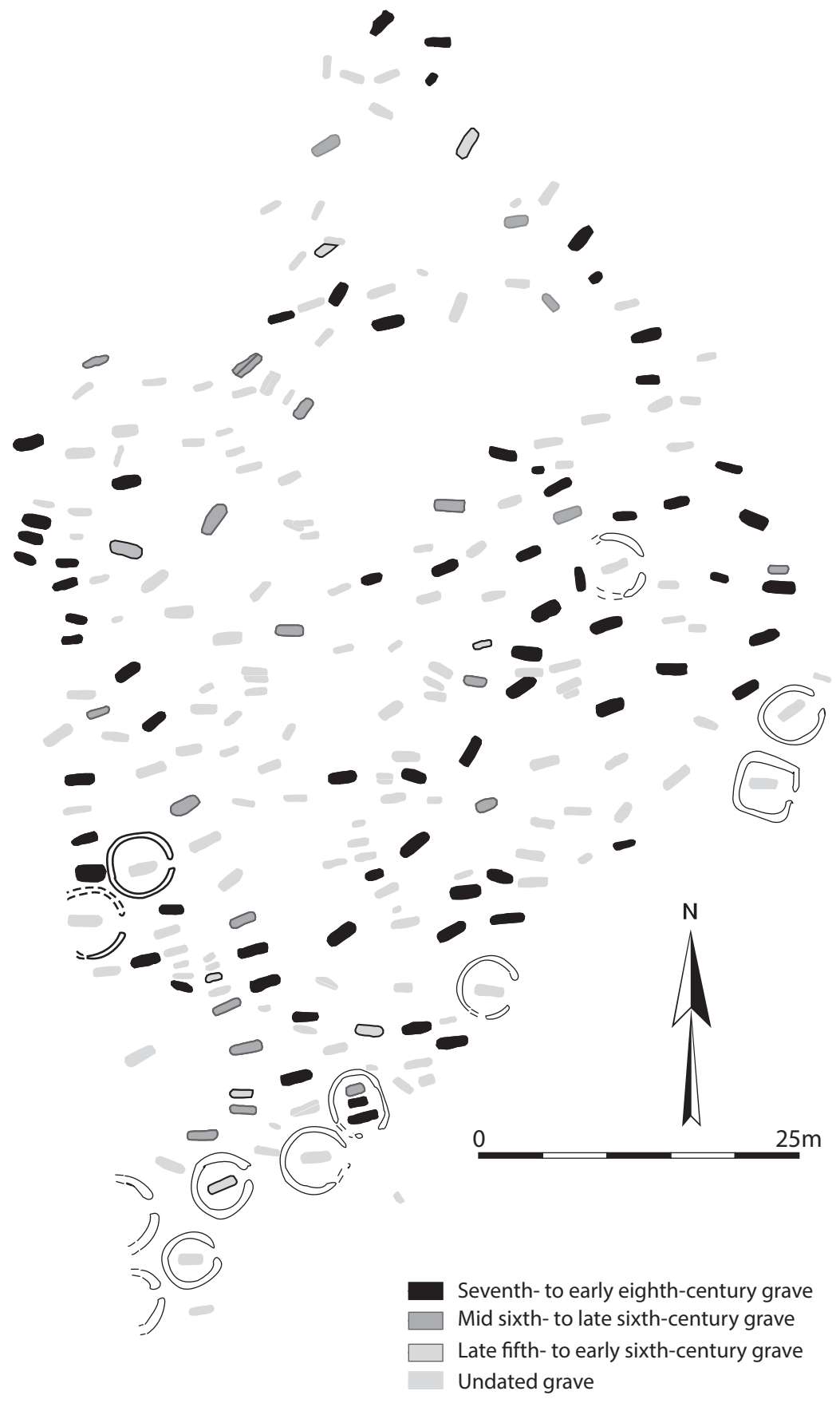

Figure 1.4 The complex chronology exhibited at Finglesham, Kent (after Sayer, 2009: Fig. 9.3). 
directions: south to north and east to west. It has also been proposed that Deal, Kent, evidenced a horizontal stratigraphy which broadly operated from west to east (Sayer, 2007). However, at both Berinsfield and Deal several graves from different dates were placed adjacent to each other, and seventh-century graves deliberately cut early sixth-century inhumations (Figure 1.5). The development of these cemeteries must have been more complex than can be explained using chronology as the primary agent of examination, and other influences and changes in mortuary behaviour also motivated the cemetery's architectures.

Berinsfield was identified as a polyfocal cemetery because two or three groups of graves each contained a cluster of furnished inhumations, and other burials were placed around them. Berinsfield consisted of two contemporary collections of graves, and both contained a core group of inhumations. Around these cores the rest of the cemetery was arranged. However, not all groups of graves were contemporary. At Deal, for example, three groups of burials were separated around a single large Bronze-Age ring ditch, the remains of a round barrow. Two of these groups of graves, north and south of the ring ditch, were contemporary and were part of a first phase which was broadly early and middle sixth-century in date. The eastern group of graves, however, was part of a second phase that was broadly later sixth- and seventh-century in date.

Using horizontal stratigraphy also tends to equate chronology with spatial patterning; however, as already shown, these two factors independently influence the mortuary landscape. For example, Evison (1987: 165) considered that Orpington, in west Kent, was composed of a horizontal development east to west from a monocentred core. Orpington had one inhumation, grave 23 , around which multiple male weapon graves were placed. The burials around grave 23 were all sixth-century, but they varied widely in date. The individuals from the latest graves found accompanied by weapons were very young or not yet born when grave 23 was constructed and when the first of the weapon graves was backfilled with earth (see Figure 1.6). This important inhumation became a focus for later burials, but the cemetery did not have an original contemporary core of graves; its centre was created through the repeated use of a particular place to inter children and men with weapons. At the same time, graves placed to the south and west of burial 23 created a multi-directional pattern. Orpington, then, is complex; simultaneously some inhumations were placed into a multi-phase core, whereas others were placed into more peripheral zones.

The spatial layout of early Anglo-Saxon cemeteries has been neglected in favour of death, objects and identities. Since the 1970s, studies which have investigated the organisation of the mortuary landscape have tended to combine interpretive discourse and spatial investigation, an 

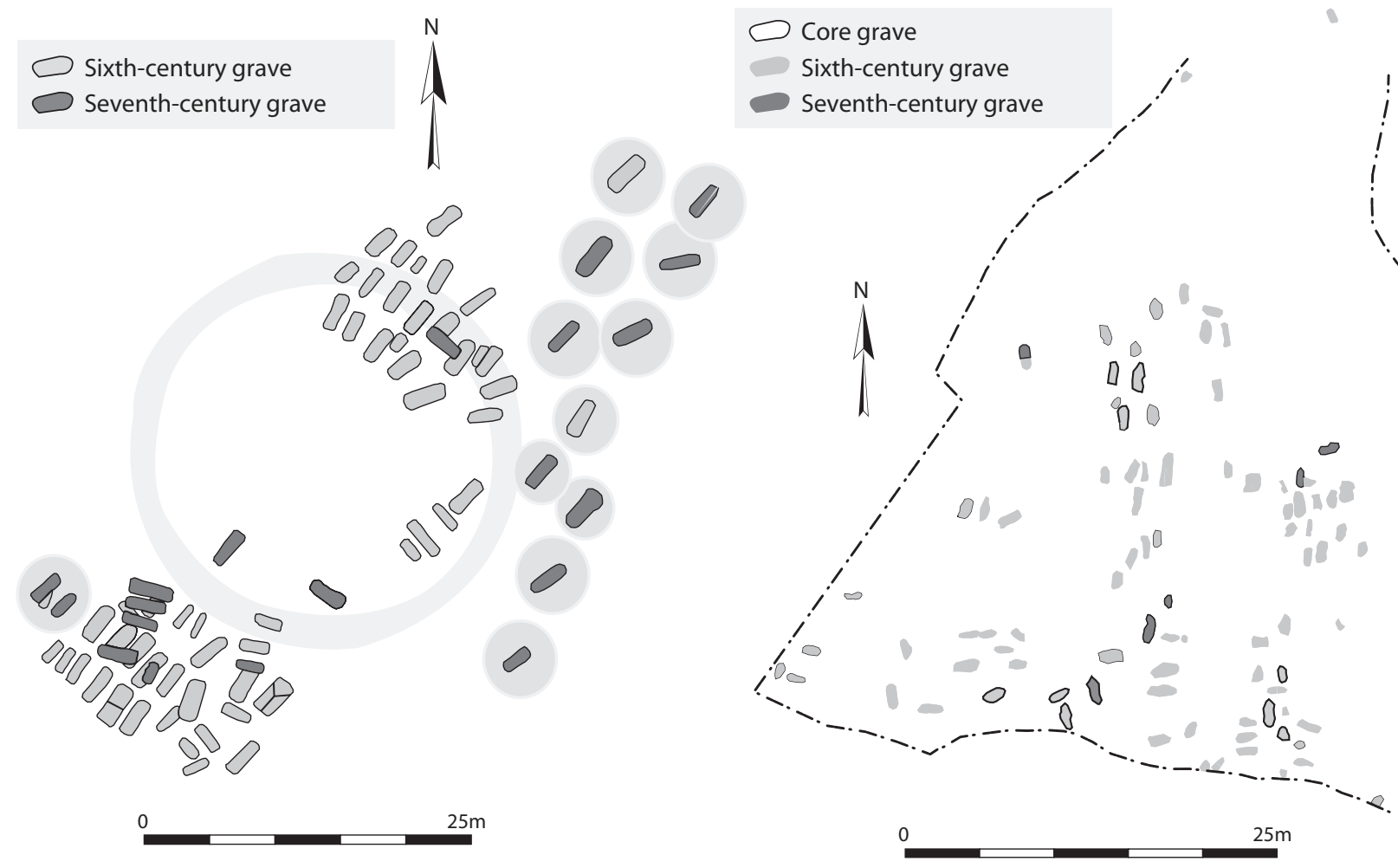

Figure 1.5 Intercutting graves at Deal, Kent (left) and Berinsfield, Oxfordshire (right). In both examples, later graves exhibited an intrusive quality, even cutting earlier inhumations. 


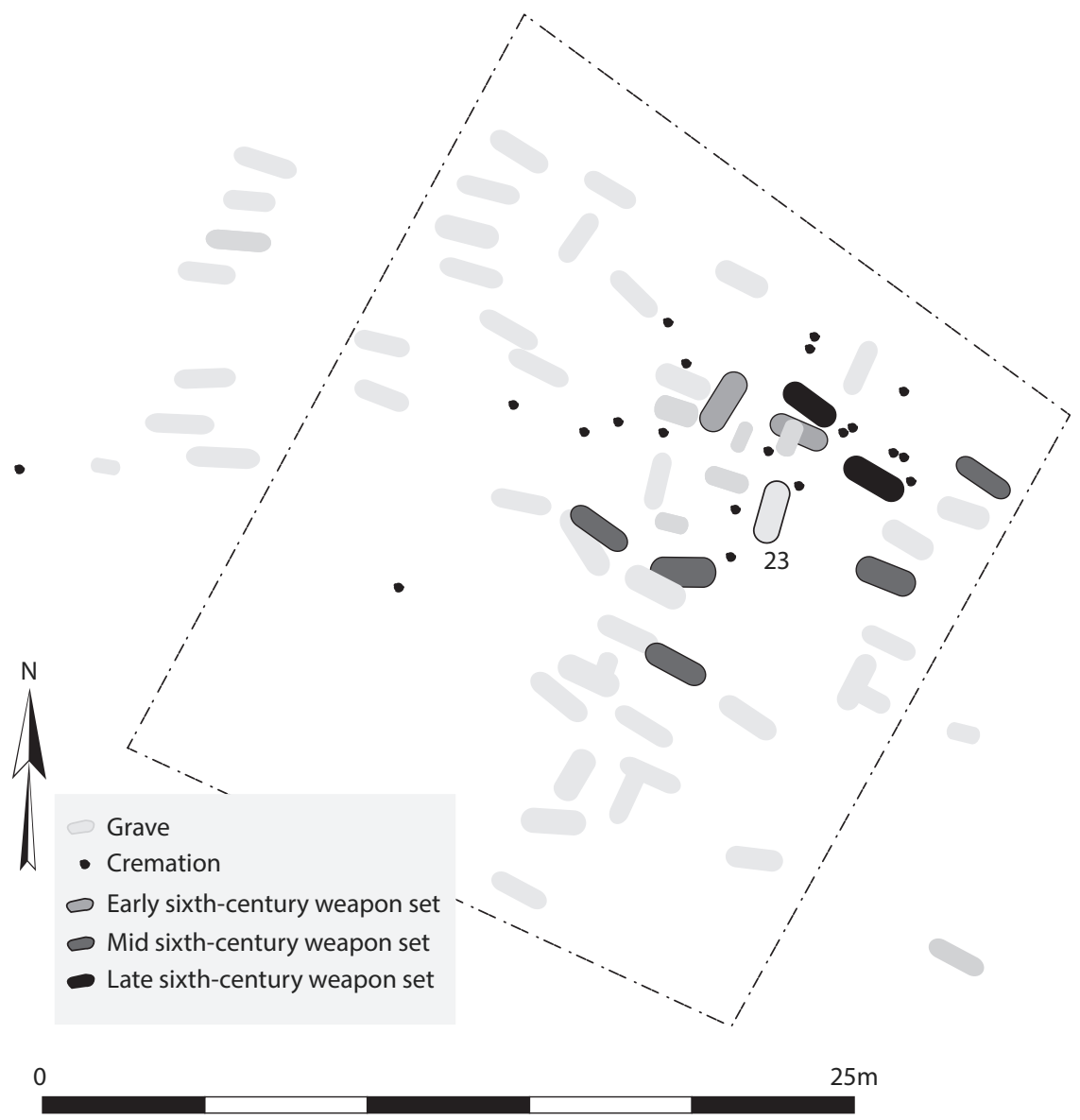

Figure 1.6 Orpington, Kent. Over the course of a hundred years or so, grave 23 was surrounded by multiple generations of weapon-set graves.

amalgamation of identity, chronology, space and belief which muddied these dimensions. As a result, few people have used space as the starting point for investigation. This book places the physical dimension of a cemetery at the centre of investigation, painting material and bodily data onto a canvas which allows for a study of mortuary behaviour and its motivations. However, space, materiality and bodies depend on time, both chronological and social. Where a grave was located, what was in it and who attended a funeral was dependent on the location of previous graves, the objects available and who was alive to contribute to the burial event (Sayer, 2010). Recent investigations into mortuary behaviour and the commemorative function of funerary semiotics have allowed archaeologists to move beyond an exploration of the individual 
dead into discussions of thy death (after Ariès, 1974: 55; 1981: 409). People make a funeral as a response to the death of another, but their behaviours and decisions encapsulate and reproduce mortuary culture and society in the moments adjoining burial and repurpose the ritualistic nature of burial to create new social identities (see Williams, 2006; Williams and Sayer, 2009; Fowler, 2010; Price, 2010). The living's response to bereavement embodies subjective decisions within the physical world because a funeral takes place at a specific time; the grave has a physical shape, and material things furnish it. But that grave does not exist in isolation: it is located in a space that includes other burials with their own histories. The very act of digging a grave enmeshes the newly dead within the narratives of a complex mortuary landscape, situating them within the materiality of the immediate past of living and changing community. The cemetery creates a tangible space which connects past generations with living populations and allows the living to construct themselves in relation to their dead.

\section{Material and social perspectives}

Entangled with ideas of horizontal stratigraphy and cemetery foci is the identification of 'founder's graves', an almost routine practice in the description of continental cemetery sites of late Iron Age or early medieval date (Härke, 2000a). A founder's grave is usually considered to be a single wealthy burial, or a pair of wealthy burials, identified as the earliest in the cemetery (Salin, 1952; James, 1979: 81-4). The identification of a founder's grave developed out of Germanic approaches to social structure based on literary sources, and is often linked to the horizontal development of a site where it is assumed that a cemetery expanded from those first burials (James, 1979; Härke, 1997). Lars Jørgensen (1987) considered this pattern to be the result of a social group, presumably a family, expressing its status with the burial of its principal parent, or parents, during the foundation of a cemetery. However, absolute dating is problematic, even with Merovingian numismatic dating, which underpins continental chronological schemes. The routine use of chronological groups with attributed artefact types means that it is impossible to definitively identify an earliest burial, and graves end up belonging to phases of costume or funerary practice (see Hines et al., 1999). In early Anglo-Saxon cemeteries, fifth-century graves are often infrequent, poorly furnished and widely dispersed, which does not suit the character of a founder's grave (Dickinson, 2011: 230).

The concept of founder's graves has not been popular among AngloSaxon scholars, but has had its supporters. Sue Hirst (1985) preferred this interpretation to Hope-Taylor's foci, where Hope-Taylor suggested 
that groups of graves or plots were centred on early features, structures, or posts now absent (Hope-Taylor, 1977). Conversely, Hirst considered that Sewerby was the focus of an aristocratic family membership cult centred on a burial plot, or plots, within the cemetery. Like HopeTaylor, Hirst complained that the absence of published sites and studies hindered the interpretation of Anglo-Saxon cemetery organisation (Hirst, 1985: 20; Hope-Taylor, 1977: 262). More recently Nick Stoodley (1999: 131-2) suggested that the burials at Andover, Hampshire, and Petersfinger, Wiltshire, were both organised around high-wealth individuals who seemed to be the central focus of burial plots; he argued that these graves were the cemeteries' founders. What is notable about this search for an originator's grave is that it often identifies the earliest wealthy burial, not the earliest burial, and as a result it might be seen as an overly romanticised approach which associates burial wealth, social status and horizontal stratigraphy.

The study of wealth and gravegoods prompted some critics to suggest that archaeologists investigate just a small number of wealthy burials in great detail, ignoring the majority of archaeological data. In the 1970s Hope-Taylor (1977: 262) lamented that many cemetery excavators were 'blinkered by their preoccupation with gravegoods'. He issued this challenge because early Anglo-Saxon archaeologists built regional typologies on objects and drew parallels between objects, not sites or people. Even studies of social stratification placed considerable emphasis on the quantity of objects found or their social value, based on modern perceptions of their meaning. For example, both J.B F. Shephard (1979), and C.B J. Arnold (1981) attributed specific importance to precious metals found within the grave. However, these approaches placed too much emphasis on archaeological data, including durable gravegoods; the amount of organic material originally included within the grave is rarely evident now, and sites like Snape, Suffolk, where some textile and other organic remains were preserved are rare (Filmer-Sankey and Pestell, 2001). In addition, archaeological categories are only of limited use for understanding early Anglo-Saxon actions; for instance, would the community who used the weapons recognise an archaeologist's definition of the weapon burial rite? The use and understanding of weapons in graves was multi-faceted and pluralistic (Sayer et al., 2019). Archaeological significance has been placed on the inclusion of a weapon or weapons in a burial, but the meanings and motivations of grave diggers might have varied between graves (Härke, 2014). For example, this variation might focus on ideas of the afterlife, personal need, personal or survivor authority, the authenticity of the weapon, the right to own or use it, warrior status, practical use, society's need for weapons or notions of masculinity, all of which 
would have intersected during graveside negotiations. These concepts and motivations have had uncertain boundaries overlapping and layering their use, and so emphasis on one or another might vary from grave to grave and from generation to generation.

The small cemetery at Orpington illustrates the problems associated with over-emphasising wealth. The cemetery, excavated in stages between 1965 and 1977, consisted of eighty-five burials, including both inhumations (sixty-five burials in sixty graves) and cremations (twenty), (Tester, 1968; 1969; 1977; Evison, 1987: 164). Orpington contained eleven adult male inhumation graves with weapons and five without (Figure 1.7). Two male burials, grave 26 and grave 23, were interred on a roughly N/S orientation (actually nearer NE/SW). Grave 26 was an early burial and included a spearhead, a knife and a shield boss, whereas burial 23 contained no gravegoods at all. However, the weapon burials found with a set of multiple weapons, for example a spear and shield, were all positioned 'enveloped' around grave 23, whereas those with

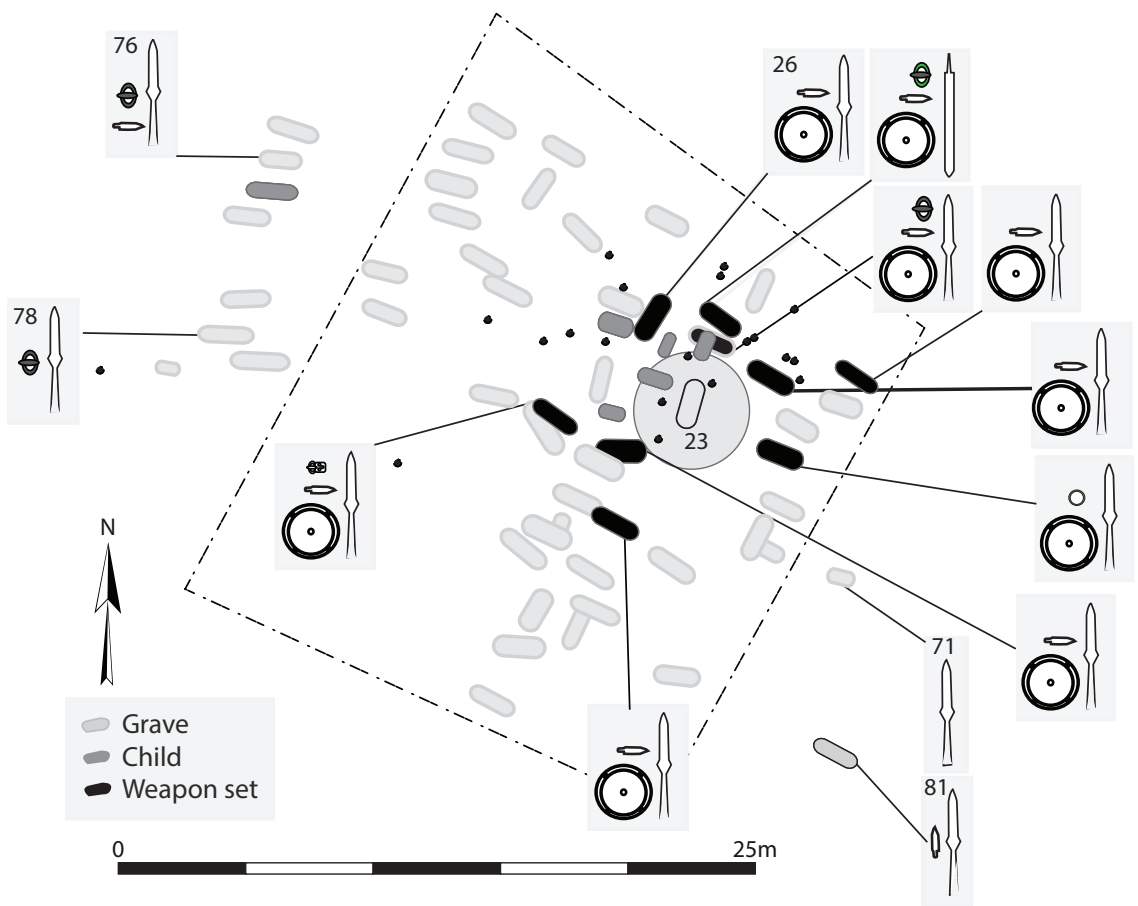

Figure 1.7 Weapon burials at Orpington, Kent. Note that grave 23 was not one of the eleven weapon burials from this site, but it was surrounded by weapon-set graves and those of children. Grave 23's continued use made it a focal point, a central place which probably had a small barrow erected over it to mark it out over generations. 
a single spear were dispersed. The majority of children's graves were found adjacent to and immediately north of grave 23. Given that it was the focus of activity, grave 23 was probably marked with a small mound visible long after the soil had been backfilled and the grave closed.

Based on the uniformity of the Orpington weapon graves, Evison (1987: 164) proposed a militaristic interpretation, suggesting that minor differences were related to grades of rank, for example the presence or absence of a buckle. However, the spatial patterning of these inhumations placed grave 23 at the heart of activity for around a hundred years, and so this group could not have been a war band of contemporaries. Grave 23 was that of an older adult, over 45, whereas the weapon burials were younger men from later periods and many of them were probably not born when grave 23 was first dug. If this group of male burials was considered a mannerbund or male society in the sixth century, then it was a mythical association, part of a continuous but overwritten narrative which was invented with the repeated placement of male weapon burials in this location. It is unlikely that this group was a contemporary uniformed military; instead the sixth-century community sought to construct a specifically masculine heritage with the appropriation of a significant ancestor. The community reinvented its mortuary tradition, introducing an inhumation grave which would become a focal point for later burials, and used it to germinate narratives about a multi-generational comitatus. The final abandonment of the cemetery may have been a deliberate rejection of this narrative, rather than motivated by religious observation.

Authors like Shephard (1979) and Arnold (1981) placed emphasis on objects and on precious metals, and yet at Orpington the three graves which contained gold or silver were all found on the periphery of the cemetery. Grave 23 had no objects and no precious metals. However, it would be unwise to assume that this absence of objects equated with inadequate access to wealth or power in life - one of the lessons from the astonishing finds of gold and art work from the Staffordshire hoard is that burial wealth may not have reflected the quality or quantity of wealth which was in circulation during the early and middle Anglo-Saxon period (Leahy and Bland, 2009). If there were larger quantities of good-quality material culture in circulation than we have predicted from burial data, then the things which are found in a grave are probably more about individuals than they are about conspicuous consumption. Of all the graves found at Orpington, grave 23 had the greatest influence on how the cemetery was to be shaped. Later narrators used mnemonic devices, like the central location or barrow, to describe the individual in grave 23 as a significant ancestor in ways that their contemporaries would have understood when retold. 
Once a grave is closed, the memory of that grave is fragile; and with the retelling its afterimage need not resemble the events and objects which constructed the original funeral, especially generations on. In practice this means that a later sixth-century funerary party might have believed that grave 23 had been furnished like the burials they prepared themselves.

We must be wary of applying modern sentiment to the interpretation of a past people; a spear can be symbolic, but it was also a weapon, a practical artefact and a tool of aggression, defence or death. But objects like knives, spears and brooches can be inalienable from a person because bodies and material jointly created appearance and provided insights into personality; many objects are inseparable from the perception of a person (Fowler, 2004; Gell, 1998; also see Harper, 2012). These objects appeared in graves, according to age, gender or life course (Stoodley 1999; Härke 1989a), and had a role to play in the material aesthetic of society because people's multi-faceted identities were intertwined with material things, visual experiences, spaces and landscapes (Gosden, 2005). Moreover, objects are part of how people define themselves and each other, and are central to how people interact.

How a person looks will influence how someone responds to them within a specific cultural setting, because objects are situated intermediately in relationships and act as fulcrums for interpersonal interactions. The aesthetic of relationships reinforces perception - for example, some of the earliest law codes describe a penalty for inappropriate gift giving in Anglo-Saxon England, as in Ine's code 29:

If anyone lends a sword to the servant of another man, and he makes off, he [the lender] shall pay him [the owner of the servant] a third [of his value]. If he provides [the servant] with a spear, [the lender] shall pay him half [of his value]. (Sexton, 2006: 67)

This seventh-century Law of Ine, King of Wessex, is important because it describes the penalty according to a weapon's blade length or its appearance; in particular, a sword brought a smaller fine than a spear but was a more potent symbol in early Anglo-Saxon allegory (Sexton, 2006: 67). This difference may have been because a sword required more training and skill to use than a spear, so a servant (or slave) would be less able to defend himself from capture. However, this may be an overly functionalist interpretation and the variations in individual circumstance which would be impossible to legislate for or enforce, since not all servants were born into servitude and many may have been taught how to use weapons by necessity or in a previous position (Pelteret, 1995). Significantly, however, this difference in the penalty 
might also have been because a servant was forbidden from using or carrying a sword and so a servant, or slave, looked incongruous with a sword but could be seen with a spear, if infrequently. A person chooses their appearance within the aesthetic of socially constructed norms, and this negotiation is subject to enduring scrutiny (Gell, 1998: 17).

Objects placed in graves are not simply gifts for the dead (King, 2004), and recent portable antiquities research suggests that, at least in Kent, objects commonly found outside the cemetery context were inconsistent with those from graves. This means that people dressed their dead especially for burial (McLean and Richardson, 2010), even if they did use older objects for burial. Dress objects found on the body were probably selected by a person or a group of people and had been chosen from a range of possibilities. They embodied aspects of how that person was perceived by those who survived them. These objects may have been inseparable from personal identity and they would have been chosen to create visual narratives because they were meaningful to the selectors (see Harper, 2012). The practicality of this is also important. An early medieval earthen grave was cut well below the ground surface; limbs, clothes and artefacts would have to be arranged and positioned or repositioned after the body was placed within it. To achieve this, an individual would have to climb into the grave in an intimate communion with the corpse, amalgamating clothing and bodies as part of an intimate, emotional and ultimately communal exhibition.

The early Anglo-Saxon cemetery at Apple Down, West Sussex, illustrates how material culture and skeletal characteristics can be combined with a cemetery plan and used to explore the social arena. The cemetery was discovered in 1981 and excavated between 1982 and 1987 by the Chichester Research Committee. It was a mixed-rite site containing inhumation and cremation burials dating from the fifth to the seventh century (Down and Welch, 1990). The decision to either cremate or bury the dead may have been the result of strategies intended to distinguish two or more separate social groups, a phenomenon seen in other contemporary cemeteries, for example Morning Thorpe, Spong Hill, Bergh Apton and Westgarth Gardens (Penn and Brugmann, 2007: 96-7). Alternatively, the choice may have been chronological, where cremation graves were mostly earlier than inhumations (see Chapter 2). Apple Down seems to be a mono-focal cemetery with central graves oriented $\mathrm{E} / \mathrm{W}$, surrounded by others oriented N/S (Figure 1.8; Sayer, 2010). Moreover, there were three distinct ways to prepare a grave at Apple Down: configuration A, inhumation graves oriented $\mathrm{E} / \mathrm{W}$ and in an interior zone; configuration $\mathrm{B}$, inhumation graves oriented N/S and in an exterior zone; and configuration $\mathrm{C}$, cremation graves found with and without urns and in two zones across the site. Of the 121 inhumations, those which employed 


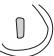

0
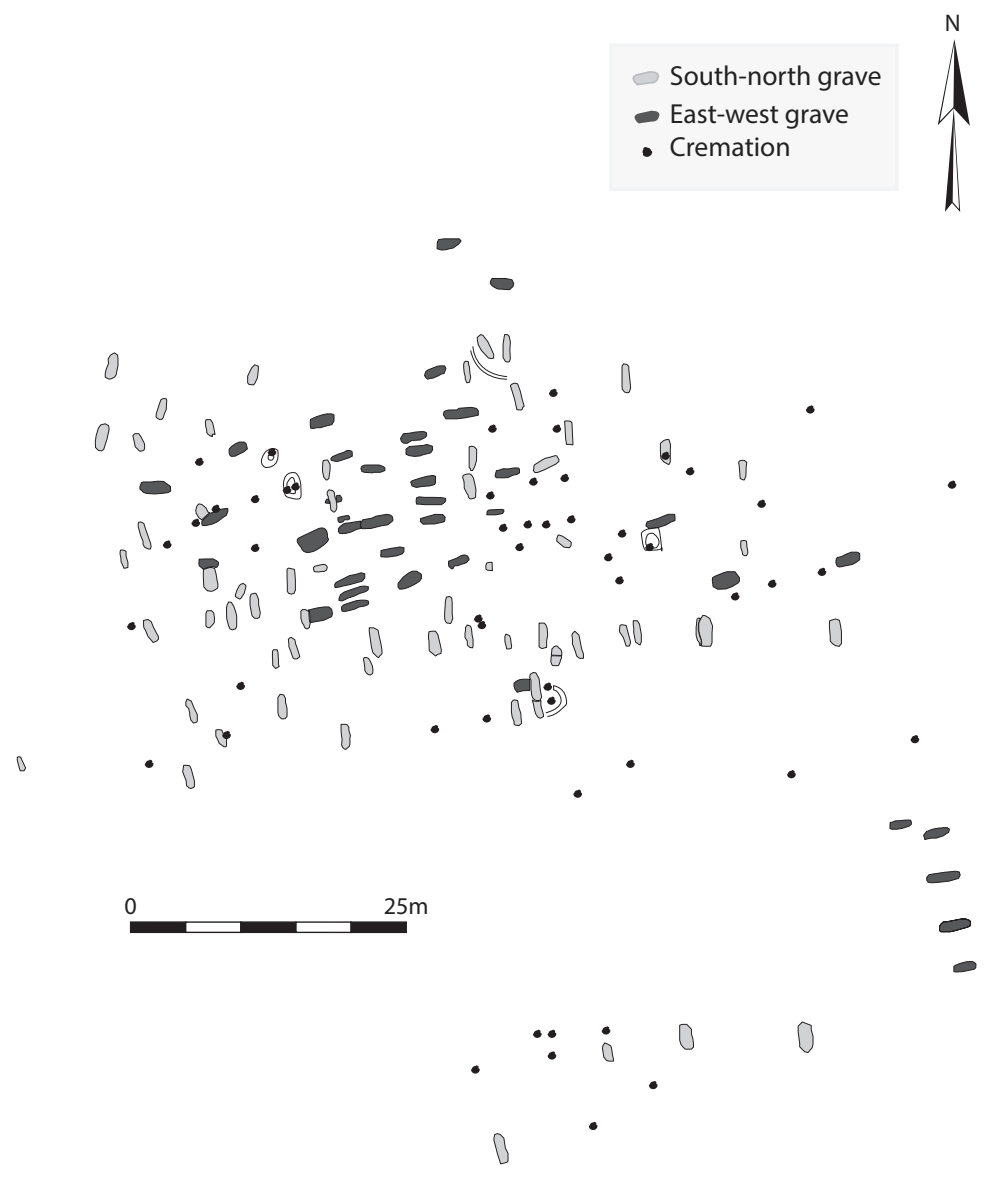

Figure 1.8 The cemetery at Apple Down, West Sussex. Grave orientation was used to define specific locations for inhumation graves at this site.

configuration A were located in the centre of the site and few of these had no gravegoods. The majority of furnished burials included a variety of artefacts, which included: swords, spears, shield bosses, seaxes, bow brooches, radiate-headed brooches, button brooches, bird brooches, saucer brooches, square-headed brooches, disc brooches, glass beakers and buckets. Configuration B, on the other hand, was more dispersed, the surviving artefacts were relatively infrequent or low in number and they included less remarkable or everyday objects like knives, beads, pins and buckles (see Figure 1.9). 


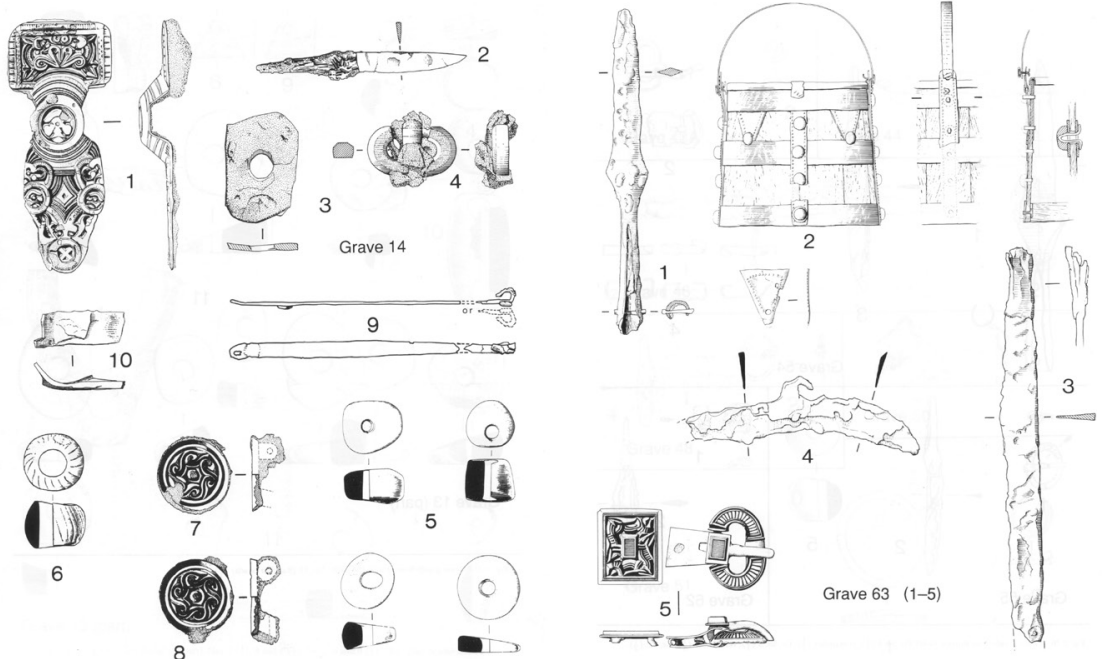

Configuration $\mathrm{A}$

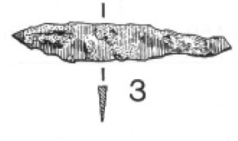

Grave 151
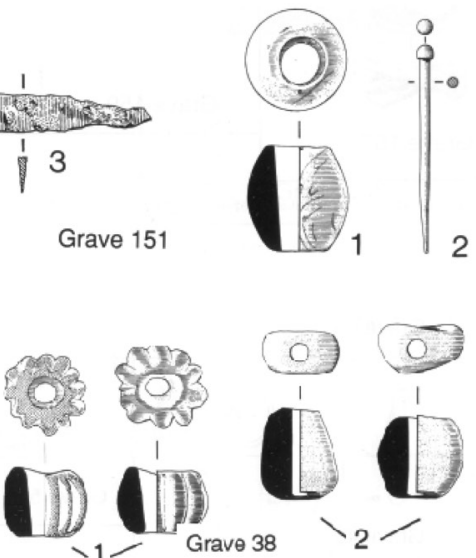

1

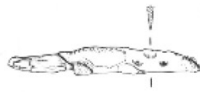

Grave 70

\section{Configuration B}

Figure 1.9 An example of the objects within the different grave configurations at Apple Down. These objects were contemporary with each other but suggest there were two distinct burial rites among the inhumation graves. 
The inhumation burials at Apple Down were separated spatially in a visually powerful way defined by both their orientation, their location and the nature of the mortuary ritual. Each configuration was provided, broadly speaking, with its own physical space and so the mortuary architects of each configuration must have had a different agenda. They created disparate funeral rites which told dissimilar narratives and resulted in a different archaeological trace used to denote social difference, which is also observable in the skeletal evidence (see Chapter 4). Configuration A included the majority of older adults aged over 45 years and most of the children's graves. One of the most striking characteristics of the configuration B burials is the relative scarcity of children's graves. The early Anglo-Saxon burial rite treated children differently to adults in the type and quantities of gravegoods (Crawford, 1999; Sayer, 2014). It is important to note that at Apple Down the children's graves mainly cluster to the west of the centre, in the middle of the cemetery, adjacent to the oldest individuals.

Of the 121 inhumations at Apple Down, twenty showed evidence of skeletal trauma - fractures, periostitis (bone infection) or swollen limbbone shafts, but only four of these (graves 14, 19, 28 and 67) belonged to configuration $\mathrm{A}$. The individuals belonging to configuration $\mathrm{B}$ had been exposed to greater physical stress and had a higher risk of injury in life (Figure 1.10). Twenty-two of the twenty-five individuals (88 per cent) showed evidence of osteoarthritis and were found to have been interred without the types of artefacts predominantly found in configuration A graves. This pattern shows there were at least two different lifeways present within the sites; the configuration A burials included a higher proportion of adults aged over 45, whose longer life spans should have resulted in a higher, not lower, incidence of osteoarthritis and trauma. Furthermore, in a reassessment of the skeletal remains at Apple Down, Annia Cherryson calculated the mean muscle mass for the skeletons based on ligament attachment sites. She observed a difference between the muscle mass of the upper limbs in adult males aged 18 to 35, with and without weapons (Cherryson, 2000: 81-7; Robb, 1998). Cherryson noticed that those without weapons (loosely equating to configuration $B$ burials) had a larger muscle mass across the whole sample. The males exposed to a higher risk of skeletal trauma had also done more physical work, enough to have increased the size of the muscle mass on their upper limbs in a different way to the males found in configuration $\mathrm{A}$ graves, those often found with full weapon kits.

Importantly, the graves around the edge of the cemetery were mostly configuration $\mathrm{B}$, but exhibited important variations. Based on the artefacts found, two graves in this zone were configuration A inhumations, but had been deliberately located on the peripheries of the cemetery. 


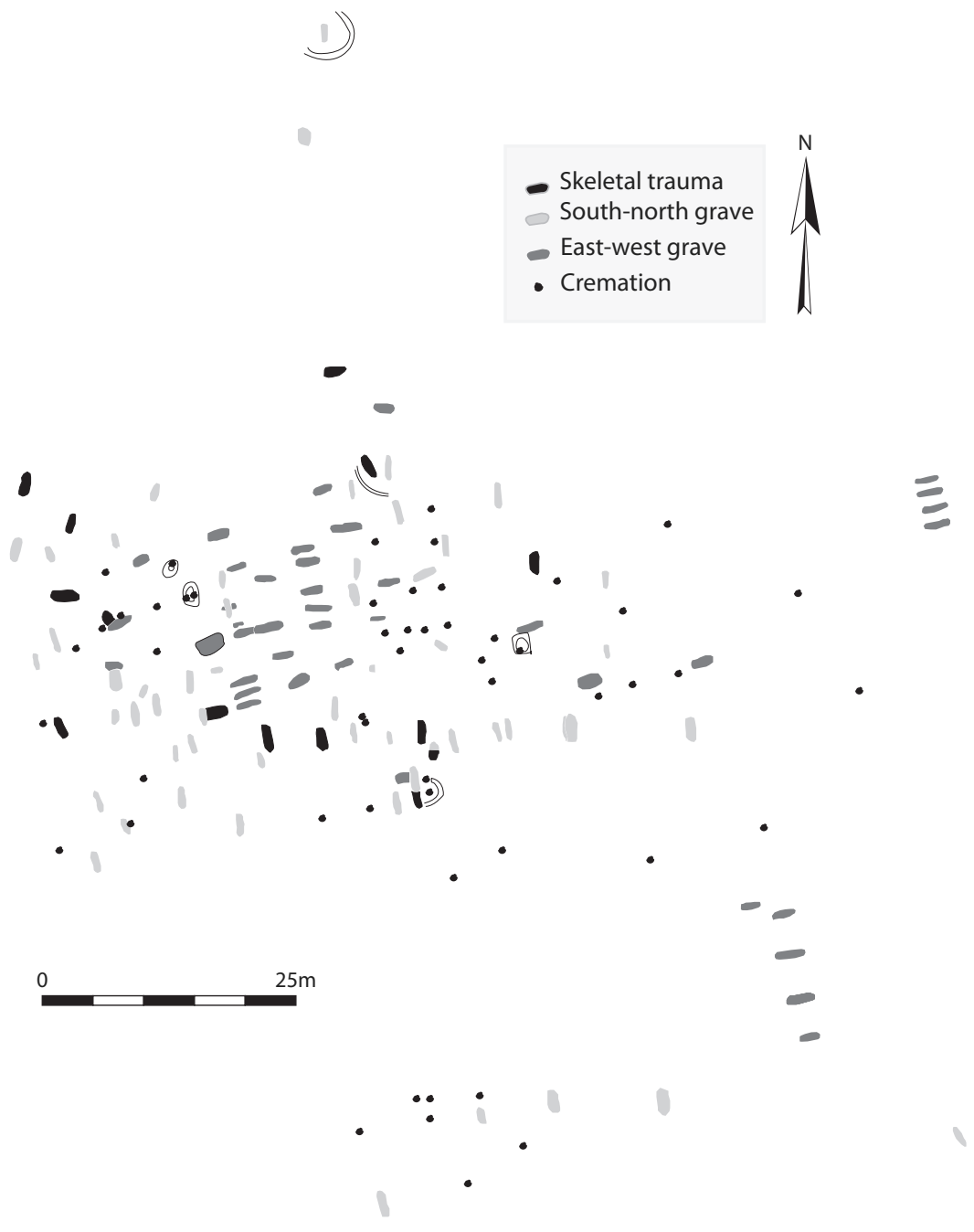

Figure 1.10 Trauma at Apple Down, West Sussex. The graves that contained evidence of skeletal trauma were found among the peripheral inhumations.

These graves (145 and 152) were both of males and both contained a full weapon kit with spear and shield. Both were positioned on an $\mathrm{E} / \mathrm{W}$ orientation reminiscent of the configuration A graves in the centre. Perhaps these two individuals belonged to the social group or household, but not to the immediate kingroup, who buried their dead in the centre of the cemetery. Five individuals $(113,121,122,126$ and 148 ) were buried with small spearheads but belong to configuration B. They did not contain full weapon kits, and burials 122 and 126 were 
both extreme outliers in Cherryson's study of muscle mass, having even larger muscle scores than the average for individuals in comparable non-weapon burials (Cherryson, 2000: 81-7). The man in burial 126 also showed signs of osteoarthritis and had a fractured vertebra. All five of these burials were found in the area of the cemetery dominated by configuration B burials, and their skeletal remains indicate a lifeway in common with those inhumations.

Apple Down was a cemetery with internal stratification according to burial ritual and location, and early Anglo-Saxon society was hierarchical, a detail that is evident in seventh-century legal codes such as Æthelberht's code:

[27]. If [a person] kills a freedman of the first rank, let him pay [with] 80 shillings.

[27.1] If he kills [one of] that second [rank], let him pay with 60 shillings.

[27.2] [For one of] that third [rank], let him pay with 40 shillings. (Oliver, 2002: 69)

These laws, and those of Hlothhere and Eadric, Wihtred or Ine preserve in a written, and therefore material form, a socially codified system of compensation outlining the value attached to a man's and a woman's life according to their status. However, that alone says very little about how this hierarchy influenced individual lives, if at all. At Apple Down, the two inhumation rituals appear to have deliberately distinguished between two groups buried together in the same cemetery and importantly, they lived different lifeways, which can be seen in the skeletal remains. Perhaps they were two separate social units.

This Apple Down case study is similar to the one from Orpington because both require us to question the validity of blanket social categories based on one strand of evidence. Although there can be no doubt that weapons were important symbols (Härke, 1989b; 1990), in both of these cases a multitude of factors influenced the final funerary assemblage. At Orpington, the noteworthy, unfurnished grave 23 seems to have been placed under a small mound surrounded by weapon burials, indicating his continuing importance to narratives told by funerary parties. The Apple Down case puts us in a different predicament; several males $(113,121,122,126$ and 148) were buried with a single spear and in the outer part of the cemetery. This zone and the greater degree of skeletal trauma within this group suggest that these people had been part of a separate and economically poorer lifeway. In the centre of the cemetery were found burials with the most wealth, also more children, but less evidence of skeletal trauma, and as a result we 
must consider that weapons were not themselves an indicator of rank. Rather, weapons encapsulated multiple ideas and singled out specific male identities (Gilchrist, 2009). Not all influential graves had spears, as Orpington burial 23 shows. He may have been buried before the full weapon kit became important to early Anglo-Saxon society, he may have been too old, his funerary party may not have been aware of this burial rite or he may not have been associated with the masculine virtues entangled with weapon burial. Equally, individuals from the poorer lifeways at Apple Down with small spears may have adopted weapon burial to enrich their own display, but this does not exclude association with a masculine identity that demanded a weapon burial. Equally, Apple Down inhumations 145 and 152 each contained two weapons, but they were outside the central burial area, and perhaps they reminded funeral participants about their separate place within living society.

\section{Negotiating social interpretations}

The previous two parts of this chapter have aimed to outline some problems with traditional monothematic archaeological interpretations and to present a holistic, multi-dimensional interpretation as an alternative. This approach was outlined in the Apple Down example, where a combination of gravegoods, mortuary space and skeletal elements provided an integrated case study. Both monothematic and multi-dimensional approaches are interpretative and seek to understand not just the creation of archaeological assemblages, but the social dynamic which made them. It is the social events within mortuary contexts, including the preparation of a body, digging a grave or contributing to a funeral, which created the archaeological record. Those events were attended by people whose decisions and actions organised and changed them. They were agents and, importantly, those agents operated within social structures that resulted in power, enslavement or reciprocal attitudes like gender differentiation, social status, kinship or belonging. In short the ability of people to influence the content of a grave, the structure of a cemetery or a social attitude is dependent on them being part of the relationships within society and social structures - for example, membership of the community or the kin group who prepared the corpse and laid it in the grave. However, individuals within these social structures are capable of conscious reflection and change; consequently it is a combination of agents and structure which affects social transformation and thereby materiality.

Inconsistent preservation and excavation methods mean that archaeology can be an imprecise science. This is true across a range of social 
sciences where the objects of study are inexact or have multiple qualities. As a result, social entities like power, gender, personhood or collective action require intellectualisation to be examined. The effect of these entities also requires conceptualisation, placing a considerable burden on abstraction in pursuit of understanding (Sayer, 1992). In archaeology this abstraction has created an apparent disharmony between agency, structuration, habitats or actor-network theories, which are measures of similar intellectual methodologies aimed at isolating internalised or externalised intentions and negotiations among past people (Robb, 2010). These social entities are embedded in the relationships between people and perhaps the ideas can be explored from this perspective. The dynamics between different generations, cultural contexts, genders and power relations enmesh individuals, places and material things with social structures and this can be used to explore the complex nature of a society.The philosopher Roy Bhaskar argued that:

people, in their conscious activity, for the most part unconsciously reproduce (and occasionally transform) the structures governing their substantive activities of production. People do not marry to reproduce the nuclear family or work to reproduce the capitalist economy. Yet it is nevertheless the unintended consequence of ... their activity. (Bhaskar, 1998: 38)

This causal agency is not embedded within social objects or individuals, but in social relations and the structures they form. For example, the powers of a university professor are not derived from their individual characteristics, but from their symbiotic relationship with students, colleagues, administrators, funding bodies and the employer or university (Sayer, 1992: 105). This will depend on a chronological context; for example, the early Anglo-Saxons did not have universities and so did not have professors. This equally applies to a multitude of other different types and shapes of institutions which structure society: land ownership, law, fostering, religion, nuclear families, prisons, servitude, class structures, gender attitude or kingship, which may exist in different forms or not at all, depending on the society in question. However, it is the associations between people which are crucial; the relation between master/mistress and servant, or king and subject, is internally necessary because each depends on the other to exist. There cannot be a monarch without subjects or a parent without children (real, deceased or metaphorical). This is not simply a social contrast or a tautology of personhood (Fowler, 2004, 2010). The servant does not give service because of social difference; it is the result of an involvement in a material social relationship. Neither master nor servant can exist without the 
other, but they can be separately identified by their contemporaries. As we discussed earlier, using Apple Down as an example, aspects of this recognition may manifest in material or physical difference between individuals.

The structuralism of the Binford or Durkheimian type was typified by the investigation of interchangeable macro phenomena, whereas the increasingly popular, but nonetheless reactionary, actor-network theory of Bruno Latour (2005) favours the micro - and proposed that actants (or agents) can be both human and non-human. This view is interesting, and increasingly built on by archaeologists either as actor-network theory (Robb, 2010) or as object-biography approaches because of the prevalence of objects within material evidence (Joy, 2009). However, Latour has been accused, like many 'recent French thinkers', of over dramatising his lines of thought, so those objects become living entities or nonperson characters in the social landscape (Alvesson and Sköldberg, 2010: 33). As archaeologists, we might consider relics to be an object where human and non-human actants have been combined. However, religious relics are saints reduced to component parts: skulls, fingernails, long bones or whole bodies. The objects are dry and anonymous, but in the context of the Catholic Church they can become the agents of pilgrimage and veneration. Without the Church these objects are human remains, but because of the symbiotic relationship between the objects, church administrators, the Catholic Church authorities and worshippers they become the subjects of veneration. It is the social structures in place within the Church, and between the Church and its worshippers, which are the agent and which provide authenticity, not the bones alone. In one of Latour's own examples (1996: 209-13), the computer processor and the red signal light which controls traffic are socially extended, forming an artefact which holds humans and non-humans together. When we stop at a red light, we are responding to the agency of a device which influences human designs (Alvesson and Sköldberg, 2010: 32). However, the red-light scenario is extremely problematic. Having acquired a driver's licence, the red light is a signal which a driver has pre-agreed means stop. He or she has entered into a social obligation to drive a vehicle within certain parameters - to obey traffic lights, speed limits and rules of conduct. The traffic light is not in fact a separate agent, but like the religious relic it is an object which embodies relationships - those between the driver and others, for example the authorities and any passengers.

As we saw with Oakington grave 78, Orpington and Apple Down gravegoods are intimate objects which were embedded with meanings and which were selected to commingle with buried bodies. Indeed, early Anglo-Saxon society placed emphasis on the aesthetic quality of material 
and dress. Sociologists have studied modern shoes in detail and as dress items they are varied and gender dependent, and they intermingle with bodies and identities in practical, semiotic and symbolic ways. As an analogy, shoes are symbiotic with the human body and have a role to play within relationships - sexy shoes, dress shoes, work shoes or sports shoes for example. Understanding this relationship between objects and people and the role of material culture in the interaction of people is important and so the sociology of shoes provides a more holistic way to understand early Anglo-Saxon dress than monothematic ranking systems based on quantity or material.

Shoes, like other apparel, are complex things consisting of multiple parts. At one level they are functional, keeping the foot warm and dry; however, shoes embody much more. They enclose and/or display parts of the body; they are status symbols; they are badges of class and group membership, which need to be learned to be used; and so they change us too (Dilley et al., 2014; Kopytoff, 1986). Progression from girl to independent woman may be marked by the freedom to wear specific shoes, heels for example, and so the selection of a shoe varies by gender and stage in life course (Hockey et al., 2014, Dilley et al., 2014).

Shoes are transformative objects used to construct the individual (Hockey et al., 2015). Likewise trainers are functional - for running, sport, informal socialising, dancing or dressing up. But they also identify a wearer's level of knowledge and engender a sense of exclusion, for example, the recognition of another skateboarder with tape or glue attached to their shoes in anticipation of damage caused by performing tricks (Steele, 1998). It can also be related to age - when the wearer lacks the semiotic knowledge shared by younger people. Equally, although trainers are used by men and women, this gender flexibility may be undermined as a woman gets older because the reproduction of asexual identities may not fit with clothing that she feels sexy or comfortable in (Hockey et al., 2015; Hockey and James, 2003). Combinations of clothing may be unacceptable, such as white trainers and a suit on a man, or alternatively they may develop a degree of acceptance depending on context, for example a charismatic or eccentric academic may 'get away with' odd combinations, whereas a business leader could not (Hockey et al., 2013). In the right combination, shoes and other clothes can produce an empowering aesthetic.

Men may wear highly polished shoes at key moments: weddings, funerals, job interviews, or simply with a dark suit in a professional role. Shoes can be status symbols which require a degree of knowledge or skill to use correctly, so shiny brown brogues require regular polishing, and Goodyear welted soles can be recognised and entirely replaced unlike 
glued soles. Like other material culture shoe construction may also merge with art and enchantment (Gell, 1992; 1998). For example, to quote the shoemaker Edward Green, 'We have half a dozen or so styles at Edward Green - most notably the Dover - which have the toe and apron carefully sewn by hand with a boar's bristle' (Green, 2017). The skill and time required to make these objects prices them as elite material culture but, like the skateboarder's shoes, only members of a specific community might have the semiotic knowledge needed to recognise particular expensive shoes.

Shoes and other apparel have multiple qualities and exist in the social world. Importantly, shoes 'need to be understood as [part of] an endlessly incomplete, embodied process' (Hockey et al., 2013: 5, 11). Objects like these are entangled with multiple forms of embodied identity; including life course, gender, sex and sexuality, materially grounded and socially differentiated, highlighting inequality which is manifested in gradations of knowledge or group membership. This fluidity of materiality mirrors Tim Ingold's (2010) concept of creative entanglement. However, contra Ingold, the material form is not itself an agent of this entanglement (Ingold, 2010: 12). Instead, embodiment is a creation of cohesive behaviours: individuals use this material culture in communication - signalling shared fraternity and reinforcing social structures. As described here, shoes are similar to all apparel, including weapons or jewellery, which are more than badges or props in social performances. They are also a metaphor for other aesthetic and physical qualities which enhance or define aspects of individual identity. These material manifestations require investment and in turn shape personae embodying inalienable identities influenced by social structures which impact on lifeways.

In modern cases there are examples of people preselecting burial costumes of their own, or choosing clothing for burial because of seasonal or specific contexts. In Sheila Harper's study of modern gravegoods one woman chose not to bury her husband in his shoes because 'shoes were for going to the doctor' (Harper, 2012: 48). Another group preferred to see a lady with her glasses on: 'She looks just like herself, doesn't she? I like her more with her glasses on' (Harper, 2012: 49). In both cases the presence or absence of objects reinforced the deceased's personhood in the eyes of the mourners. In these examples the use of an inalienable object within a grave required particular people to contribute, for example:

'We've put something in his top pocket, if that's alright.' I say: 'Whatever it is, is it to go with him?' He says: 'Yeah. It's just a cigarette, like. He liked a cigarette.' I say: 'That's not a problem.' The eldest brother says: 'No lighter, though. He'll have to get a light off someone else up there', and he gestures towards the sky as he says this. As they leave one of the 
other brothers says to me: 'Thank you. He looks fantastic.' They walk out. When I go through and check the chapel, I see that, aside from a single cigarette, they have put a shot-sized bottle of Jack Daniels in Mr Atkinson's breast pocket as well. (Harper, 2012: 56)

One case study, often discussed by undertakers on the University of Bath's Death and Society Master's degree, was the inclusion of teddy bears and other objects in children's coffins, and the increasing need to have larger coffins for children to accommodate the extra material added for burial. By contrast, a crematorium might not allow a teddy bear to be cremated because burning artificial fibres is banned by many local authorities' environmental policy. The inclusion of a bear, shoes, glasses or cigarettes might depend on who dictates the funeral process. In the previous example, the wife may have disliked shoes because of her own values, or perhaps she associated her husband with a home environment; if they were an older couple, they may have left the house infrequently and only in a negative context, to see the doctor towards the end of his life. But the man's daughter might not have felt the same. As a result, we must see gravegoods as the end product of an ongoing social negotiation, not just between the funerary participants, but also other actant structures (like the crematorium or local government). But these processes are individual and specific and so may not always be obvious to archaeological enquiry.

Within the social world, objects and spaces may have multiple meanings where people have multiple disparate identities concurrently. Social archaeologists (like sociologists and anthropologists) are habitually challenged by situations in which multiple things happened simultaneously. It is therefore not possible to remove one factor, gender for example, from a mixture of other forces which include kinship, age, status or family and which might act on people's behaviour or perceptions. What is important is to recognise that the social world is not a fixed entity, but is in a state of constant unrest. This fluidity can be seen most obviously in archaeology, as opposed to sociology or social anthropology, because its subjects come from sites which span tens or hundreds of years and are not snapshots of social systems explored using focus groups, surveys or ethnographic observation. Archaeology is well placed to explore relations through societal change because society is not static, but consists of elastic identities expressed in a variety of ways which evolve and change over time, and it is this change that is identifiable.

Many of the underlying processes seen with shoes can also be considered for other objects which intersect with and enhance bodies: weapons, clothing or jewellery, for example. The spears from Apple Down and Orpington were not simply symbols added to a grave to 
signal rank or legal status. Like shoes, weapons were an extension of the person. A sword is worn perhaps regularly on a baldric or belt, so is visually associated with a person, and its shape may alter with wear, by a hand resting on it adding a patina and character (Sayer et al., 2019; Brunning, 2019). When being worn, a sword may affect its wearer's stance, changing the body posture, and when it is left to one side a person may feel vulnerable, disempowered or naked. A spear regularly practised might leave calluses on its user's hands. Practice, as well as combat, is a physical activity with dangers that might leave recognisable scarring that could become part of a person's personality.

Both spears and swords need knowledge to use. Spears may have been hafted locally, with a handle cut from local wood, its head riveted or attached depending on local method or tradition. A whetstone is required to keep any blade sharp, and it might be wrapped, protected from the soil when it was placed into the grave; for example, grave 37 from Snape or the wrapped three-spear bundle also found at Snape in grave 47 (Filmer-Sankey and Pestell, 2001). Early Anglo-Saxon spearheads are iron, so they had to be maintained, cleaned and looked after. A well-worn but well-maintained weapon conveys semiotic knowledge, whereas a broken haft, a haft of inappropriate size or a rusted or bent spearhead might engender exclusion or indicate a lost skill; for example grave 158 from West Heslerton, East Yorkshire, was accompanied by a spear with a deliberately bent blade. In the grave spears may be found alone, but swords are most often found in conjunction with other weapons. Out of the 534 weapon burials studied by Härke, 237 included just a spear whereas only nine examples included a solo sword, and there were sixty-two swords in total in this sample (Härke, 1989b: 56). Like shoes, swords might be visually empowering in weapon combinations, but jarring or disempowering when seen alone or with the wrong clothing and equipment.

Spears are transformative objects - a person holding a spear could be a guard, a fighter, a hunter - and the spear might be a threat, a danger or a reassuring presence. Previous studies show that weapons probably conveyed gender identities and were used in different ways over the life course (Stoodley, 2000; 2011; Härke, 1997). Early Anglo-Saxon swords were pattern welded; their fittings were often changed and some had great age before being buried. Epic poems describe swords as a 'hero's weapon' (Bone, 1989). Equally, however, some spears were pattern welded or carried embossed decoration or symbols, for example the ring-and-dot decorated spear from grave 51 at Great Chesterford, Essex (Evison, 1994: 150) - so while all swords probably carried cultural enchantment some spears were equally distinct, or made special with pattern welding or added decoration or symbols (Gell, 1992). 
Leslie Alcock (1981), Rainer Christlein (1973) and J. F. Shephard (1979) directly associated weapons with rank. However, it is unlikely that specific subdivisions of rank were symbolised by weapon combinations, or by combinations with other material culture as with Evison's interpretation of Orpington (Evison, 1982: 165). Like dress shoes, the presence of a weapon in a grave probably embodied masculinity and formality. It conveyed authority and the knowledge to maintain and use it. That knowledge was gained from social associations, being taught, learning by copying and practice with comrades, and so a weapon conveys connection and association. The five small spears in graves 113, 121, 122, 126 and 148 from Apple Down may have been included because of their connection with social structures, masculinity and weapon use. Nonetheless they were outside the central areas of the cemetery, a phenomenon also seen at Orpington where graves 71, 76, 78 and 81 were neither spatially nor material similar to the other weapon burials (see Figure 1.7). All four of these graves were placed away from the centre of the burial ground. In both of these cemeteries the single spear entangled multiple qualities with overlapped messages. Importantly then, the spear did not convey the same associations for all people all of the time; instead it was a complex artefact with multiple layers of meaning which functioned differently within different social structures.

Anthropologists describe living society, and in a lived context weapons or clothing may help to construct the personhood of an individual. A person may choose to construct themselves using semiotic knowledge (Fowler, 2001: 160; 2004; 2010). In the mortuary context, however, it was social structures - shared cultural approaches to gender, age, common identity groups and local community - that dictated the nature of relationships and influenced how a person was treated, what they were buried with and who contributed to the material aesthetic of commemoration. The agents influencing burial existed (and exist) within the relationships between people and the relationships between objects and people.

\section{Conclusion}

Society has a pluralistic quality, which means we do not always know which combination of social factors is determining the archaeological record. However, social phenomena exist in history and geography, and meanings can be transient. Archaeologists see chronological phenomena muddied by preservation and recognition. We might understand how a particular quality changed in local, regional and national settings and how this quality was situated in relation to similar phenomena. What is harder to understand is what underlies a particular material pattern, but 
this does not suggest that social complexity, multiple determinations and ambiguity mean woolly interpretation. Socially situated phenomena like belief, personal motivation or affinity exist within material situations; they empowered actants with agency and created material expression, using the conceptual tools available, to create recognisable tropes or patterns in practice that others might also recognise in actual or conceptual terms. Together, objects and social relationships have causal powers which produce leitmotifs, shared themes, within and between sites and across different scales.

Each funeral event is different from the last; the dead are dissimilar people, and the social relationships and participants might be changed. But at each event there are similarities - participants have a relationship, and their social world is being reproduced by communication and interaction. Their individual attitudes towards status, gender, age and kinship have been shaped by interactions and relationships created or defined by social structures in the form of agreed canons. These principles are renegotiated as social situations are confirmed or challenged, creating new semiotic knowledge shared between participants. Objects are symbiotic to this situation because they are an aesthetic essential add-on to the layered and textured experience. In grave 78 at Oakington we saw a concealed touch, an act of body positioning which created knowledge and obscured it under a sleeve. The touch may have been a performance meant for just a few members of a subgroup of funerary participants, united with a shared memory and a shared connection to the deceased. Equally, the weapons located in the Apple Down and Orpington graves were part of an aesthetic combination appealing to the participants because they epitomised the qualities of a shared social class. Even at these two sites, spears had multiple meanings, appearing both in weapon combinations and singly within the graves of different people buried in separate areas of the cemeteries.

In doing social archaeology we are not comparing objective scientific phenomena, but events, outlooks and decisions with multiple qualities, so we must use qualitative and quantitative approaches simultaneously. For a cemetery this means a holistic approach because it explores artefacts and bodies together. A multi-dimensional perspective might employ spatial and temporal understandings, and a multiple-scale approach investigates single graves, cemetery patterns or regional distributions. With multiple methods applied to complementary evidence we can glimpse the shape of the social process which created observable phenomena. This chapter is an introduction to the philosophical perspective which underpins this book. Each community used its conceptual tools to create a unique site and they employed a language using grave orientation, chronology, grave plots and mounds to express that message. 